Waste Glass Corrosion Modeling:

Comparison with Experimental Results

\author{
William L. Bourcier
}

November 1993

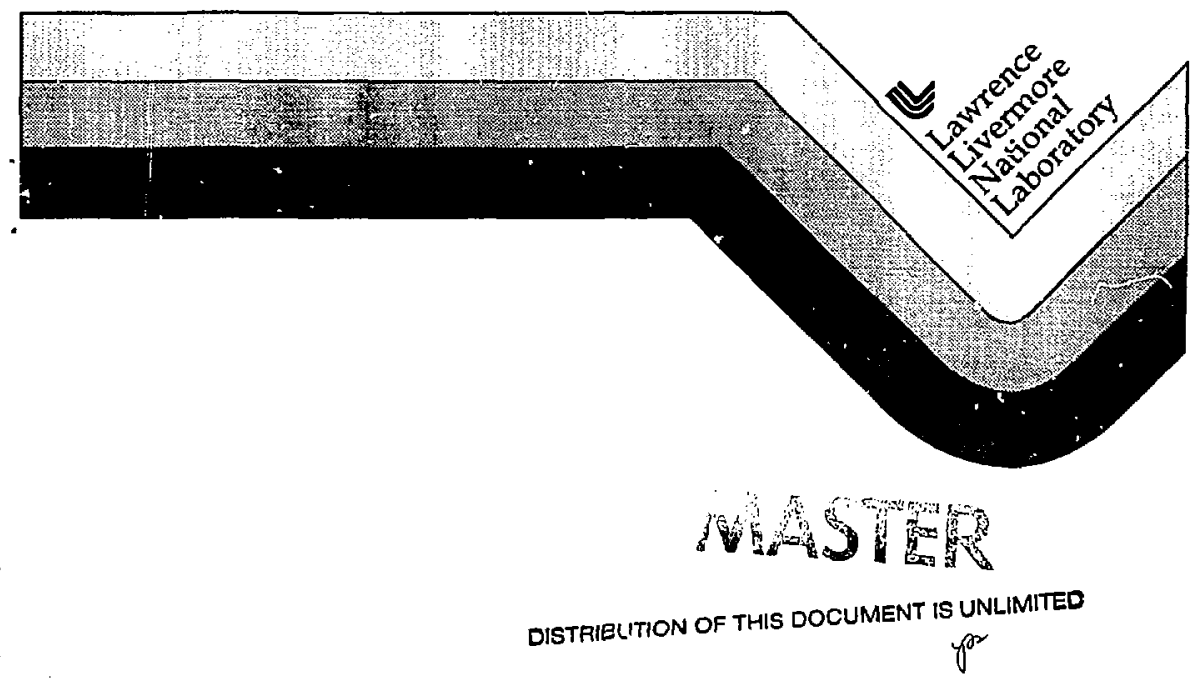




\section{DISCL,AINER}

Worh performedi undet the suspices of the US. Depurtment of Eatrgy by Lawence Livermore National Laboratory under contract number W-3405-ENG-48.

This document was peepared es an account of work spansored by an agency of the United States Goverament. Neither the United States Gasernment nor the Unirersity of California nor any of their employees, makes any vartents. express or implied, or assumes any legal liability or responsibility for the aceurres, completeness, or usefulness of any information, apparatus, produch, or process disclosed. or represents that its use nould not inrringe privately onned rights. Reference harein to any speclïic crmmereial products, process, or service by frode rane, trac emerk, manufacfurer, or otherwise, does not neressersl; constitute or imply its endorsement, ri: anmendation, or faroring by the United States Gevernment or the Unisersily of Collfornta. The views and opinions of oulhors expressed hereln do not nexessarily state or reflect those of the Linited States Covernment or the Unirersity of Celifornia, and shall not be used for adverising or product endorsement purposes. 


\title{
WASTE GLASS CORROSION MODELING: COMPARISON WTTH EXPERIMENTAL RESULTS
}

\author{
WILLIAM. L. BOURCIER
}

Lawrence Livermore National Laboratory, L-219, Livermore, CA 94550 USA

\begin{abstract}
Models for borosilicate glass dissolution must account for the processes of (1) kinetically-controlled network dissolution, (2) precipitation of secondary phases, (3) ion exchange, (4) rate-limiting diffusive transport of silica through a hydrous surface reaction layer, and (5) specific glass surface interactions with dissolved cations and anions. Current long-term corrosion models for borosilicate glass employ a rate equation consistent with transition state theory embodied in a geochemical reactionpath modeling program that calculates aquecus phase speciation and mineral precipitation / dissolution. These models are currently under development. Future experimental and modeling work to better quantify the rate-controlling processes and validate these models are necessary before itie models can be used in repository performance assessment calculations.
\end{abstract}

\section{INTRODUCTION}

A chemical model of glass corrosion will be used to predict the rates of release of radionuclides from borosilicate glass waste forms in high-level waste repositories. The model will be used both to calculate the rate of degradation of the glass, and also to predict the effects of chemical interactions between the glass and repository materials such as spent fuel, canister and container materials, backfill, cements, grouts, and others. Coupling between the degradation processes affecting all these materials is expected. The glass corrosion model must therefore be mechanistic, and not a simple empirical extrapolation of experimental glass degradation rates. Empirical extrapolations cannot be extended with confidence to repository time frames of over 10,000 years, and the multiple coupled interactions cannot all be explored experimentally in a reasonable time period.

The purpose of this paper is to provide a summary of current work on developing chemical models for borosilicate glass corrosion. We start with a brief overview of the glass corrosion process and then show how chemical models hav 2 been applied to a variety of glass corrosion experiments. This summary focuses on dissolution behavior of borosilicate glass compositions currently anticipated for use as waste forms under repository-relevant conditions. The models described here cannot be expected to predict glass corrosion rates under conditions significantly different from these.

\section{OVERVIEW OF GLASS CORROSION PROCESSES}

Figure 1 illustrates the major processes taking place during glass corrosion. The reaction initiates with water diffusion into the glass and alkali ion exchange. Evidence for water diffusion comes from SIMS and ion probe profiling of reacted glasses which show diffusion profiles for water in a surface zone generally less than 1 micron thick ${ }^{1,2}$. Ion exchange is indicated by the early rapid release of alkalis relative to other glass components which is commonly observed in glass dissolution tests ${ }^{3}$. Hydration and ion 
exchange result in the formation of two layers on the glass surface; an inner diffusion layer where concentration gradients for alkalis and water are observed, and an outer hydrated "gel layer" where network hydrolysis (breakage of $\mathrm{Si}-\mathrm{O}-\mathrm{Si}$ ) bonds takes place. The gel layer is depleted in alkalis and boron and enriched in insoluble elements such as $\mathrm{Al}, \mathrm{Ca}, \mathrm{Mg}$, and heavy metals (e.g. actinides).

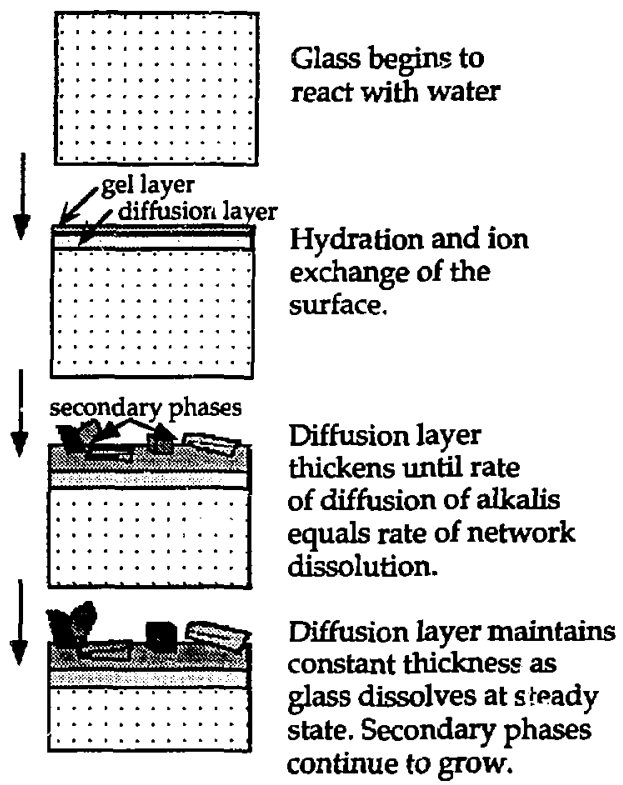

Figure 1. Glass dissolution mechanism.

With time, some elements released into solution re-precipitate on the hydrated glass surface and elsewhere as a variety of secondary phases. These phases are commonly clays, zeolites, and metal oxides/hydroxides. The reaction of glass to form secondary phases is driven by the thermodynamically unstable nature of glasses. Water allows glass to react and transform into a set of crystalline phases which are thermodynamically more stable. Water acts as a flux and allows the glass to react at a measurable rate. Under anhydrous conditions, evon glass compositions that are relatively non-durable in water are stable for billions of years 4,5 .

Steady-state conditions are commonly observed during glass dissolution where the rates of water diffusion and ion exchange are equal to the rate at which the glass network dissolves. Steady state conditions are evidenced by the tendency for the glass diffusion layer to remain constant in thickness while the glass dissolves away and the mass of secondary phases increases with time ${ }^{6}$. In open system experiments, the rate of 
release of most elentents is approximately constant or slowly decreasing with time. In closed system experiments, the release rates slow down more rapidiy with time due to "saturation" effects, the buildup of dissolved glass species in solution (Fig. 2). Increased silica concentrations are the primary reason for decreased dissolution rates ${ }^{7}$ dithough other elements have an effect as well ${ }^{8}$. Elemental releases from glasses in closed system tests also show non-stoichiometric behavior, some elements are reieased much more rapidly than others (Fig. 2). Most of this non-stoichiometry is due to the precipitation of the less soluble glass components as secondary mineral phases, although a small amount is accounted for in the formation of leached layers.

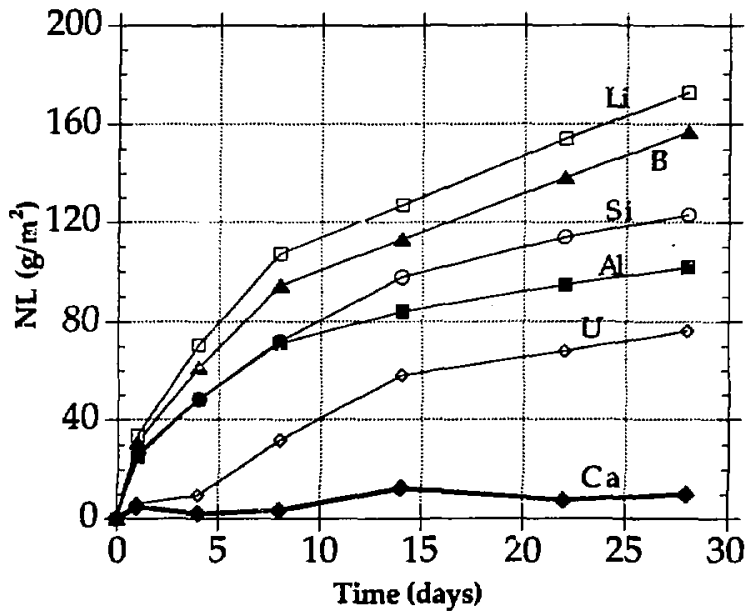

Figure 2. Normalized elemental release from SRL-165 glass reacted in $0.003 \mathrm{~m} \mathrm{NaHCO}$ at $150^{\circ} \mathrm{C}, \mathrm{SA} / \mathrm{V} 0.01 \mathrm{~cm}^{-1}$.

Nuclear magnetic spectroscopy (NMR) shows that network dissolution reactions taking place in the gel layer are complex. ${ }^{17} \mathrm{O}$-doped experiments show that both breakage and re-formation of $\mathrm{Si}-\mathrm{O}-\mathrm{Si}$ linkages are taking place ${ }^{10}$. Hydrolysis of the highly stressed glass structure allows relaxation and removal of incompatible elements. The original glass is transformed into a hydrous silica-rich phase plus local areas enriched in transition and other heavy metals such as actinides which eventually crystallize into a variety of solid phases, or are released into solution. In some flowthrough glass dissolution tests, the gel layer appears to serve as a transport barrier that limits the overall dissolution rate ${ }^{11}$. However, in most closed-system experiments, elemental release data and electron microscopic examination of the surface layers show that the overall reaction rate is not controlled by diffusion of elements through the alteration layers $7,12,13$.

Recent NMR data has also shown that boron in waste glasses is clustered into boron-rich regions ${ }^{14}$. Boron occurs in both three and four-fold coordination with alkalis 
in a sodium di-borate-type structure. The hig:. reactivity and solubility of these zones gives rise to the relatively rapid release of boron from borosilicate glasses in waste glass leach tests.

Rates of glass dissolution may also be strongly affected by certain dissolved elements. For example, dissolution rates of silicate glasses are strongly decreased in the presence of dissolved $\mathrm{Mg}, \mathrm{Pb}$, and $\mathrm{Zn}$, and strongly enhanced, under some conditions, by dissolved $\mathrm{Fe}$ (see below). Likewise, anions such as phosphate and sulfide are known to affect mineral dissolution ratns and may likewise affect glass dissolution rates. Depending upon the specific metal, these effects may be attributable to several processes; the formation of surface complexes, the precipitation of a surface layer providing a transport barzier, or the reaction of dissolved glass species with the dissolved metals causing the precipitation of colloids or secondary phases which affect the glass dissolution affinity ${ }^{15}$. These types of effects are potentially important in repository environments where a variety of dissolved species will be present from other repository materials.

In summary, a model for borosilicate glass dissolution must account for the following processes: (1) kinetically-controlled network dissolution, (2) precipitation of secondary phases, (3) ion exchange of selected elements, (4) in some cases, rate-limiting diffusive trausport through a hydrous surface reaction layer, and (5) specific glass surface interactions with dissolved cations and anions. This set of coupled processes should be able to quantitatively predict observations of glass dissolution which include the saturation effect (glass dissolution rates slows down as dissolved glass species build up in solution); the increase in $\mathrm{pH}$ which accompanies glass dissolution in closedsystem tests; the variability of glass dissolution rate as a function of glass composition; and rate-affecting interactions of the glass surface with dissolved cations and anions. We will first look at examples of how the five processes are incorporated into current models and then critically review modeling results using a representative set of examples for modeling of experimental data.

\section{MODELING OF GLASS CORROSION}

Current long-term corrosion models for borosilicate glass employ a rate equation consistent with transition state theory emboulied in a geochemical reaction-path modeling program that calculates aqueous phase speciation and mineral precipitation/dissolution. These models ignore early diffusion-controlled dissolution behavior which is more important for less durable glass compositions such as alkalisilicates and is important only in the very early stages of reaction of borosilicate waste glasses. Diffusion in this case refers to solid state diffusion of ions through the partially hydrated glass surface layer, not diffusion of aqueous species through the more hydrated and re-structured gel layer. We therefore do not discuss the many studies which solve the equations for the formation of a moving and thickening transportlimiting surface layer.

\section{The Rate Law}

The rate law commonly used to model network hydrolysis, assumed to be rate controlling during glass dissolution, has the general form ${ }^{16}, 17$ :

$$
\frac{d n_{i}}{d t}=A v_{i} k \prod_{j} a_{j}^{-a}\left(1-e^{\left(\frac{\hat{a}}{\text { akt }}\right)}\right)
$$


where $n_{i}$ is the number of moles of species $i$ in solution released from the glass, $t$ is time, $A$ is the reactive surface area of glass, $n_{i}$ is the concentration of species $i$ in the glass, $k$ is the rate coefficient for the glass, $\prod_{j} a_{i}^{-n}$ is the product of the activities (concentrations) of dissolved aqueous species which make up the activated complex of the rate-limiting microscopic dissolution reaction, $A$ is the reaction affinity defined as $\operatorname{RTln}(Q / K)$ where $Q$ is the activity product and $K$ the equilibrium constant for the rate-determining glass dissolution reaction, $\sigma$ is a stoichiometric factor that relates the rate-controlling microscopic reaction to the overall solid dissolution reaction (usually it is assumed $\sigma=1$ ) $R$ is the gas constant, and 1 is the temperature in Kelvin. The form of Eqn. 1 predicts that the dissolution rates of solids have the following characteristics: (1) the amount of solid dissolved is proportional to exposed surface area, (2) the dissolution rate slows down as the solid approaches saturation, and (3) the dissolution rate is constant under conditions far from saturation $(Q / K \ll 1)$. An expression having this general form is used in all of the major glass modeling computer codes at this time (e.g.

PHREEQE/GLASSOL ${ }^{11}$, EQ3/6 $6^{9}$, DISSOL ${ }^{18}$, REACT, ${ }^{19}$ LIXIVER ${ }^{20}$.

This rate law implies tnat at equilibrium there is a reversible microscopic dissclution reaction which is rate-limiting. However, because glass is thermodynamically unstable and cannot reach saturation, the overall glass dissolution reaction is clearly not reversible. Therefore, when this rate law is applied to glass dissolution, it must be applied not to the overall reaction, but to some rate-limiting microscopic reversible reaction.

Many of the parameters in Eqn. 2 are not known either from theory or from experiments, so that in practice the equation is simplified to:

$$
\frac{d n_{i}}{d t}=A v_{i} k(p H)\left(1-\left(\frac{Q}{K}\right)^{\prime}\right)^{\prime}
$$

where the product term $\prod a_{j}^{-n}$ is reduced to include only the $\mathrm{pH}$ dependence of the rate coefficient, and the affinity expression is simplified and re-expressed in terms of the saturation index $(Q / K)$ of the dissolving solid. T?.is form of rate law is commonly used as an expression to which experimental elemental release data are fitted, i.e. values of $k$, $K, r$ and $s$ are determined by regression of experimental data.

Current modeling codes may further simplify Eqn. 2. GLASSOL assumes no solution compositional dependence of $k$, which is assumed to vary only with temperature. DIS $X_{0 L}, \mathrm{EQ} 3 / 6$, LIXIVER, and REACT treat $k$ as a function of both $\mathrm{pH}$ and T. No models account for any further dependencies of $k \mathrm{cn}$ solution composition as indicated in Eqn. 1 above.

To use Eqn. 2 to predict glass dissolution rates, ar. assumption must be made as to what phase becomes saturated in order to evaluate the $Q / K$ term. Several phases have been iried, ranging from the initial unreacted glass composition ${ }^{9,18}$, to the composition of the alkali-depleted surface layer ${ }^{21}$ to simple hypotheticai silica phases $11,22-24$. It is clear from these modeling studies that using the unreacted glass composition gives results that deviate from experimental observations (see below). However, the other two approaches give comparable agreement with experiments.

\section{Secondary Phases}


Precipitation of secondary phases takes pl $\lrcorner$ ce as glasses dissolve and the concentrations of species build up in solution. Geochemical modeling codes used to model glass dissolution incorporate algorithms that track saturation states for these possible mineral phases and predict the most stable phase assemblage based on mineral thermodynamic data. The types and amounts of phases are continually adjusted during the reaction path ralculation to maintain the most stable phase assemblage. While this approach works well for simulations of high-temperature hydrothermal systems, experience has shown that this approach often leads to incorrect phase assemblage predictions for the lower temperature $\left(<150^{\circ} \mathrm{C}\right)$ glass dissolution tests 25.9 . Thermodynamically less stable phases tend to precipitate instead.

Alternative methods of predicting secondary phases nave therefore been used in the simulations. One method, termed "inverse modeling", uses the measured solution composition to identify which phases are near saturation ${ }^{26}$. These phases are then assumed to be those actively precipitating and controlling the solution composition, and only these phases are then allowed to precipitate during the glass reaction. Another approach is to simply restrict the database of mineral phases allowed to precipitate to those actually observed experimentally. Obvinusly neither approach has any predictive capability for secondary phases, but no reliable theory is currently available to enable predictions of the most likely secondary phases in these complex systems (see Steefel etal. ${ }^{27}$ for a possible new approach).

\section{Ion Exchange}

The formation of secondary phases is the primary cause for the observed nonstoichiometric release of elements during glass dissolution. However, the formation of an alkali-depleted surface layer also contributes to non-stoichiometric release and also affects the $\mathrm{pH}$ of the solution through ion exchange reactions:

$$
\text { Glass }-\mathrm{Na}^{*}+\mathrm{H}^{*}=\mathrm{Na}^{+}+\text {Glisss }-\mathrm{H}^{*}
$$

Similar reactions take place for other alkalis including lithium, potassr um, and cesium. The ion-exchanged zone has variable thickness depending on the glass composition and test conditions, but is generally a cc::ple microns or less in extent. The net effect of the ion exchange reaction is to raise the $\mathrm{pH}$ of the surrounding soistion. The $\mathrm{F} H$ effect is bigger as the surface area to volume ratio $(\mathrm{SA} / \mathrm{V}$ ) of the test increases (Fig 3).

Although the ion exchange process is complex and involves jiffusion of ions and water through a partially hydraled and inhomogeneous medium, the chemical effect of the process can be modeled simply. And unless the ion exchange process is rate limiting, oniy the chemical effects need to be incorporated into the model. A simple method for incorporating this effect first suggested a few years ago ${ }^{28}$ was recently reported ${ }^{19}$. In this approach, an ion exchange reactant in addition to the glass reactant is used in the simulation. This reactant is composed only of the elements released during ion exchange. The mass of this reactant is fixed by the experimentally measured thickness of ion exchanged zone. The reactant is allowed to react rapidly at first to simulate the rapid initial formation of an ion exchanged zone. The predicted $\mathrm{pH}$ and elemental concentration of species predicted using this method agree fairly well with experimental results (Fig 3). Also, the results show that inclusion of ion exchange effects is only necessary for simulations of fairly high SA/V ratio.

Transport-limited corrosion 
Experimental evidence suggests that under certain flow-throigh test conditions, the dissolution rate of some glasses is controlled by transport. Grambow ${ }^{11}$ has hypothesized that it is the transport of silica through the surface alteration layers which is rate-limiting. The transport-limited rate is modeled by a simple diffusion law:

$$
r_{1}=\frac{D}{L}\left(a_{s}-a_{b}\right)+r_{\text {sin }}
$$

where $\left(r_{t}\right)$ is the dissolution rate, $D$ and $L$ are the diffusion constant and thickness of the hydrous alteration layer, $\left(a_{5}-a_{b}\right)$ is the dissolved silica concentration gradient across the layer from the surface (s) to the bulk solution (b). rfin is the "final rate", an

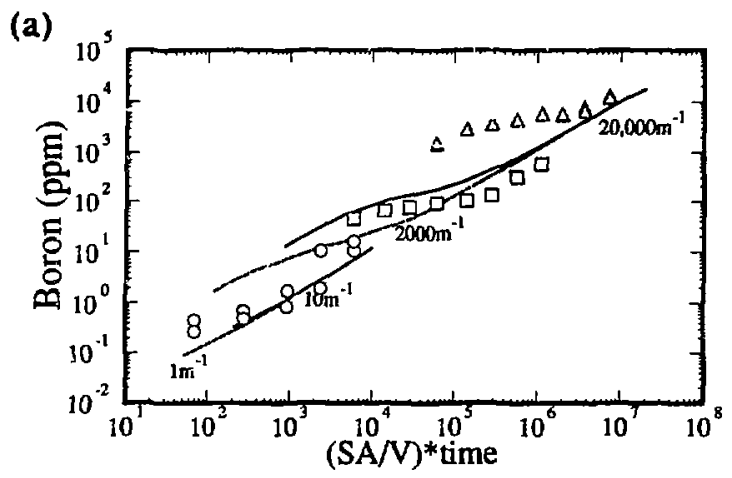

(b)

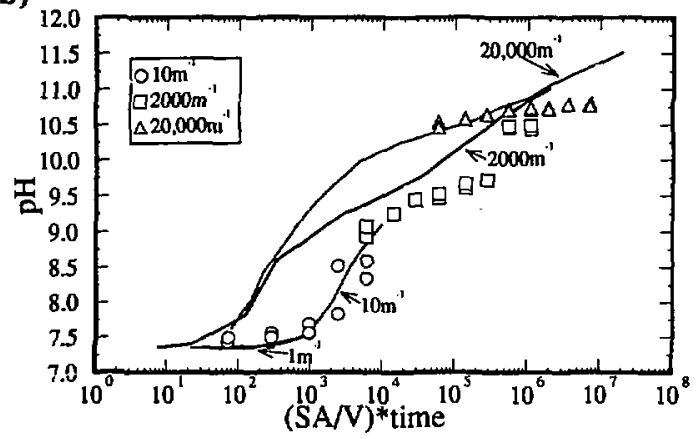

Figure 3. Calculated (lines) and measured (symbols) boron (a) and $\mathrm{pH}$ (b) released from SRL-131 glass in EJ-13 water at $90^{\circ} \mathrm{C}$ vs. $\log$ (SA/V time). Data from ${ }^{29}$ for $S A / V$ ratios of 10,2000 , and $20,000 \mathrm{~m}^{-1}$. Calculated curves for 1 and $10 \mathrm{~m}^{-1}$ are identical. 
experimentally estimated empirical paramete: to account for the observed finite rate of glass reaction even at "saturation" where Eqn. 1 would predict zero reaction rate.

The affinity-based rate control (Eqn. 2) is combined with this simple diffusion rate control in the FLASSOL model ". The model tests for whether the rate is controlled by transport or surface reastion and makes the appropriate calculation. Delage et al. 20 have also combined transpor' and affinity-based rate control in the LIXIVER code. In their model, the thickness and rate of silica diffusion through the gel layer control the concentration of silica at the gel layer/solution interface, which they use for the value of ' $Q$ ' in Ern. 2. This arproach thus assumes that silica diffusion through the gel layer affects the concentration of dissolved silica at the gel/solution interface thereby coupling the effects of silica transport and affinity sate control.

\section{Surface Interactions}

No current glass dissolution models explicitly account for spevific surface interactions between glass and dissolved aqueous species. These effects are specific to certain elements, such as the effect of dissolved $\mathrm{Mg}$ and $\mathrm{Zn}$ to slow glass dissolution rates ${ }^{30}, 31$. Some attempts have been made to understand and model deviations in dissolution behavior believed to be due to surface complex formation $32,15,33-35$, and others). Explicit provision for surface interactions will be especially critical in order to account for coupled effects of glass with other repository materials in performance assessment calculations.

\section{Glass Composition}

In current models, the effect of glass composition on glass dissolutio- rates is accounted for in two ways. Glass has an intrinsic du rability related to its composition and structure. Quantification of this property affects the rate parameter, $k$, in Eqn. 1. The glass composition also afiects the value of the equilibrium constant, $K$, in the affinity term of the rate equation. The value of $K$ used in the model depends on which dissolution reaction is rate-controlling.

Several approaches have beer used to try to account for the effect of glass composition on glass corrosion rate. These include using "hydration theory" ${ }^{36}, 37$ to calculate both the rate coefficient and the equilibrium constant $K^{38}$, by calculating $K$ from estimated thermodynamic properties of the surface layer ${ }^{21}$, by experimental determination of the rate coefficient from flow-through tests ${ }^{39}$, and by empirical fits to experimen'tal tata in order to determine both $k$ and $K^{11}$.

Although the success of hydration theory in correlating glass durability with glass thermodynamic properties has been documented ${ }^{40}$, the theory has been less successful in mivising quantitative predictions in g!ass corrosion models 9,18 . When incorporated into glass corrosion models, the free energies of formation of glasses (which determine the value of $K$ in Eqqn. 2) raiculated using hydration theory do not predict any slowing of glass dissolution rate as saturation is approached. The value of $K$ is predicted to be too large.

Alternatively, Grambow used hydration theory to estimate the rate coefficient in the rate equation ${ }^{38}$ using the expression:

$$
k_{f}=X \epsilon^{\left(-E_{*} / R T\right)} e^{\left(-\Delta C_{,}(\xi) / R T\right)}
$$

where $E_{a}$ is the activation energy for dissolution (determined experimentally), and $\Delta G_{r}$ is the ivgriation free encrgy for the glass dissolution reaction. The first term ini the 
equation $\left(X \exp \left(-E_{a} / R T\right)\right.$ is an Arrhenius term that accounts for the effect of temperature on the rate constant. The second term $\left(\exp \left(-\Delta G_{r}(\xi) / R T\right)\right)$ corrects the rate constant for the effect of glass composition. This approach has had limited success when dealing with the compositional range of real waste glasses. It was eventually drapped from the Grambow model and replaced with experimentaliy determined values for specific glass compositions.

Another way to apply the hydration free energy model so glass dissolution is to assume that the rate-limiting step in glass dissolution is the dissolution of the surface alkali-depleted hydrous layer. The thermodyrannic properties or this layer can be approximated by assuming it is a solia solution of amorphous components ${ }^{21}$. In this method, the hydration free energy is applied to the surface alteration layer rather than the unreacted glass, and the components are chosen to be amorphous rather than crystalline in order to be structurally and energetically more similar to the amorphous surface layer. This model better predicts the experimental glass dissolution rates than does the hydration free energy model applied to the unaltered glass. However, the reiationship between starting glass composition and glass dissolution rate in this modei is complex. The composition of the alteration layer (which is used to calculate the glass dissolution affinity and therefore dissolution rate) is affected both by the glass composition arid solution composition. No attempt has yet been made to quantify this effect in the glass dissolution model. The composition of the alteration layer is determined by analysis of reacted glasses.

\section{Deviant glass dissolution behavior}

Several studies ha\%e shown that glass dissolution rates may abruptly increase in rate after showing normal behavior over extended pericids of time at what appeared to be nearly constant "final" dissolution rates $41,29,42,43$. These rate changes may be accompanied $\mathrm{k} y$ abrupt changes in $\mathrm{pH}^{43}$ and the onset of precipitation of new secondary phases ${ }^{29}$. The rate changes are not well understood, bu: may be related tc physical changes in the surface layers ${ }^{44}$, secondary phase precipitation ${ }^{29}$, or as yet unidentified processes.

\section{MODEL APPLICATIONS}

The purpose of modeling is to make long term predictions of glass corrosion rates under repository conditions. The first step in validating a model is to test tie modul's prediction of short term experiments. A higher degree of validation is achieved by demonstrating that the model is capable of accurately predicting glnss dissclution test results from a large variety of glass dissolution experiments where parameters such as temperature, SA/V, flow-rate, leachate composition, and oth- $s$ are varied over the range expected for a nuclear waste repository. The development oi a model is therefore an iterative process where chemical and physical processes are added to the model or existing ones modified to better predict the results of glass tests. Validation tests and corrosion experiments continue until a satisfactory level of agreement is obtained.

The most extensive validation test yet performed for a glass corrosion model is the application of the geochemical modeling code GLASSOL to experimental data for the glasses JSS-A, ABS-118, and RTT7 ${ }^{34}$. These glasses have been subjected to a variety of dissolution tests orer $\mathrm{A} S \mathrm{~S} / \mathrm{V}$ range of 10 to $10,000 \mathrm{~m}^{-1}$, in distilled water, silica-doped water and granitic groundwater, under static and flow-through conditions, with and without the presence of bentonite and magnetite, and for durations of up to one year. 
The GLASSOL code was used to simulate the'e tests results using rate laws given by Equns. 2 and 4.

When using GLASSOL, model parameters are obtained from the set of test results also used to validate the model. The forward rate constant $(\mathrm{k})$ was obtained from the initial reaction rate from the low SA/V $\left(10 \mathrm{~m}^{-1}\right)$ tests because these are farthest from silica saturation and should therefore have the highest initial reaction rate. The silica saturation constant $(K)$ is obtained from the high SA/V tests which are closest to silica saturation where the reaction rate is slowest. The value of $\mathrm{K}$ regressed from the test data at $90^{\circ} \mathrm{C}(-2.93)$ is close to the solubility product of Cristobalite $(-2.75)$ which is the silica polymorph most similar to silica glass in structure (Cristobalite is the silica phase on the liquidus at the glass transition temperature). The final rate $\left(\mathrm{r}_{\mathrm{fin}}\right)$ is also obtained from the highest SA $/ V$ tests. The diffusion constant for silica through the gel layer is obtained from regression to data from flow-through tests. These are the four parameters needed by GLASSOL to predict glass corrosion rates. Fig 4 shows experimental data and model predictions of GLASSOL for (a) closed-systera tests and (b) open system tests at $900^{\circ} \mathrm{C}$ using this set of parameters. The agreement is within about $40 \%$ for boron and $20 \%$ for silica.
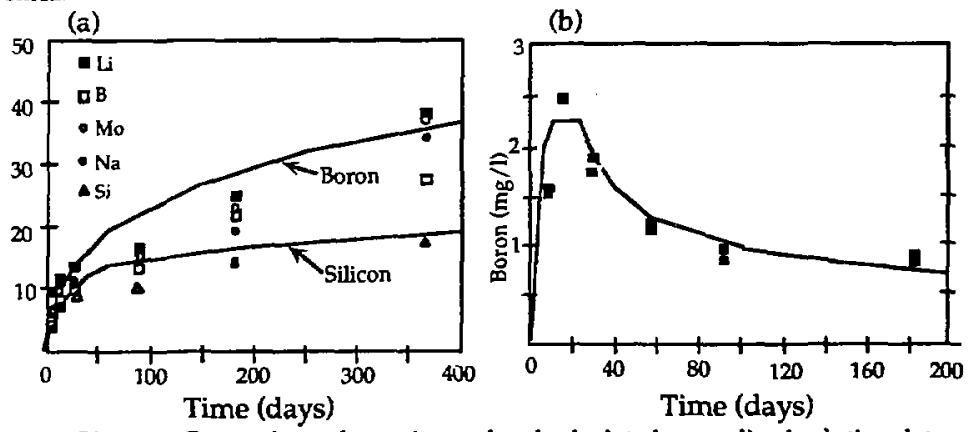

Figure 4. Comparison of experimental and calculated normalized solution data for elements released from $R T T 7$ glass at $90^{\circ} \mathrm{C}$ in (a) DI water, SA $/ V=10 \mathrm{~m}^{-1}$ and (b) flowing DI water at $2.9 \mathrm{ml} /$ day $^{34}$.

\section{LIMITATIONS OF CURRENT MODELS}

The most important problems of current models fall into three categories: (1) the fact that most model parameters are obtained from the same experiments as those being modeled, (2) the lack of a precise definition of the concept of "silica saturation", and (3) the poorly defined and quantified long-term release rate. These areas need to be addressed with additional experimentai and modeling work.

Although the GLASSOL approach has successfully predicted glass corrosion tests rescilts, some questions have been raised as to its suitability for long-term predictions. Curti ${ }^{45}$ used the GLASSOL code to model the dissolution of the French COGEMA and British MW borcsilicate glasses in order to assess whether GLASSOL can be applied to safety analysis of the Swiss high-level waste repository. Curti found three areas where improvement was needed before GLASSOL could be suitable for safety analysis, these 
included: (1) better accounting for the effects of silica sorption on bentonite backfill, (2) inclusion of provisions for partitioning radionudides into alteration phases (currently stcichiome'ric release is assumed), and (3) the problem that the final rate of corrosion is poorly defined and has no mechanistic basis. Curti alsc: notes that "a significant drawback of the modeling exercises reported ... is that the relevant parameters $\left(k, R_{f i n}\right.$, $K$ are derived ad hoc from the experiment to be modeled."

The most serious limitation of these three is that of estimation of the long-term or "final" reaction rate, both in terms of providing a mechanism controlling this rate and a numerical value to be used in modeling. More recent work by Grambow ${ }^{46}$ illustrates this problem using data from dissolution tests in saline fluids and suggests that the rate control may switch frorn surface reaction control to water diffusion control over long time periods. Clearly the exact mechanism which controls dissolution rates over long time periods is not yet known.

Godon et al. ${ }^{47}$ have observed that RTI7 glass dissolution in contact with eleven different materials shows no systematic "silica saturation" level. Although the dissolved silica concentration reaches a nearly constant value in each test, that value varies greatly from test to test depending on the type of additional material present. The "silica saturation" level therefore is not a parameter related to glass composition only, but also depends on test conditions. The silica saturation levol for a particular test probably results from a balance between the rate of formation of silica-containing secondary phases (including colloids) and the rate of release of silica from the glass. The silica saturation value $(K)$ from equation 2 above is therefore not a constant for a given glass corr:position but will change as a function of test conditions. Long-term predictions based on a constant value of $\mathrm{K}$ in the rate equation are therefore of questionable reliability.

\section{CONCLUSIONS}

It is clear that further progress in developing quantitative predictive models for glass dissolution depends on obtaining results from systematic interpretable experiments that confirm and zuantify the postulated glass reaction mechanisms. Some work has been done in this are: 48,39 but much remains to be done. Some specific suggestions for future work are given in ${ }^{49}$ and include:

(1) Flow-through tests of glasses in continuously stirred reactors with controlled $\mathrm{pHs}$ which are designed to measue the rate constant for glass dissolution over a matrix of temperatures, pHs and glass compositions. Similar tests should be performed in $\mathrm{pH}$ buffer solutions doped with relevant cations and snions to systematically determine the effects of dissolved species on coissolution rate. These tests should be combined with surface titrations to characterize glass surface speciation.

(2) Closed-system tests of a matrix of glass compositions with controlled $\mathrm{pH}$ (pH stat) to invosigate the effect of glass composition on glass dissolution rate under conditions where secondary phases form (unlike the flow-through tests above). These tests should be combined with nuclear magnetic resonance (NMR) analysis of unreacted glasses in order to correlate glass structure and coordination with glass durability as measured in both the fiovi-through and closed system tests.

(3) Additional closed system tests should be performed where stable recondary phases such as calcite, quartz, and clays are added to control solution composition. The data from these tests should help to define and quantify the affinity term in the rate expression. 
(4) Molecular orbita! calculations of glass $s$ urface speciation and molecular dynamics simulations of glass dissolution benavior should be performed to help constrain macroscopic glass dissolution models and support validation of proposed dissolution mechanisms.

Ir. all cases, experiments should include as complete an analysis of both solid and aqueous phases as possible. Too many experiments have bren performed where incomplete characterization of either solids or solution phases have made interpretation of the results ambiguous, both for mechanistic interpretation of the results, and for use of resuits in model validation attempts.

The results of these experimental investigations should be combined with additional model development to produce a workable and sufficiently comprehensive glass dissolution model for use in repository performance assessment sinnulations.

\section{ACKNOWLEDGMENTS}

This work was supported by the U.S.D.O.E. Office of Environmental Restoration and Waste Management, under contract W-31-109-ENG-38 through Argonne National Laboratory.

\section{REFERENCES}

(1) V.M. Oversby and D.L. Phinney, J. Nuc. Materials, 190, 247-268 (1992).

(2) T.A. Abrajano and J.K. Bates, Mat. Res. Soc. Symp. Proc., 84, 533-546 (1987).

(3) J.E.(. Mendel, "Final Report on the Defense High Level Waste Leaching Mechanisms Program", Pacific Northwest Laboratory, PNL-5157, (1984).

(4) L.C. Klein, in Advances in CeramicsAmerican Ceramic Society: 1986; Vol. 20; pp 693-698.

(5) H.C. Palmer, K. Tazaki, W.S. Fyfe and Z. Zhou, Geology, 16, 221-22 (1988).

(6) T. Abrajano, J.K. Bates, W.L. Ebert and T. Gerding, "The effect of gamma radiation on ground water chemistry and glass leaching as related to the NNWSI repository site.", Argonne National Laboratory, SANL-510-001, (1986).

(7) L.A. Chick and L.R. Pederson, Materials Research Society Symposium Proceedings, 26, 635-642 (1984).

(8) W.L. Bourcier, H.C. Weed, S.N. Nguyen, J.K. Nielsen, L. Morgan, L. Newton and K.G. Knauss, in Seventh Annual Water-Rock Conference; A.A. Balkema: 1992; pp 81-84.

(3) W.L. Bourcier, "Geochemical modeling of radioactive wasteglass dissolution using EQ3/6: Preliminary results and data needs", Lawrence Livermore National Laboratory, UCID-21869, (1989).

(10) B.C. Bunker, D.R. Tallant, T.J. Headley, G.L. Turner and R.J. Kirkpatrick, Phys. Chem. Glasses, 29, 106-120 (1988).

(11) B. Grambow, "Nuclear waste glass dissolution: Mechanism, model and application.", JSS Project, Swedish Nuclear Fuel and Waste Management Co., 87-02, (1987).

(12) T. Murakami, R.C. Ewing and B.C. Bunker, Mat. Res. Soc. Symp. Proc., 112, 737-748 (1988). 
(13) T.A. Abrajano, J.K. Bates, A.K. Woodland, J.K. Bradley and W.L. Bourcier, Clays and Clay Minerais, 38, 537-548 (1990).

(14) B.L. Phillips, in ANL Technical Support Program for DOE Environmental Restoration and Waste Management. Annual Report October 1991-September 1992. J. K. Bates, Ed.; Argonne National Laboratory: 19;3; Vol. ANL-93/13; pp 153-164.

(15) G.L. McVay and C.Q. Buckwalter, J. Am. Cer. Soc., 66, 170-174 (1982).

(16) P. Aagaard and H.C. Helgeson, Am. J. Science, 282, 237-285 (1982).

(17) A.C. Lasaga, J. Geophys. Res., 89, 4009-4025 (1984).

(18) T. Advocat, J.L. Crovisier, B. Fritz and E. Vernaz, Mat. Res. Soc. Symp. Proc., 176, 241-248 (1990).

(19) W.L. Bourcier, W.L. Ebert and X. Feng, Proceedings of the Materials Research Society Symposium, (1993).

(20) F. Delage, D. Ghaleb, J.L. Dussossoy, O. Chevallier and E. Vernaz, J. Nuc Materials, 190, 191-197 (1992).

(21) W.L. Bourcier, D. Peiffer, K. Knauss, K. McKeegan and D. Smith, Mat. Res. Soc. Symp. Proc., 176, 209-216 (1990).

(22) T. Advocat, J.L. Crovisier, E. Vernaz, G. Ehret and H. Charpertier, Mat. Res. Soc. Syrip. Proc., 212, 57-64 (1991).

(23) E.Y. Vernaz and J.L. Dussossoy, Appl. Geochem., 1, 13-22 (1992).

(24) L. Michaux, E. Mouche and J.-C. Petit, Appl. Geochem., 1, 41-54 (1992).

(25) C.J. Bruton, Mat. Res. Soc. Symp. Proc., 112, 607-619 (1988).

(26) B. Grambow and D.M. Strachan, "A comparison of the performance of nuclear waste glasses by modeling", Pacific Northwest Laboratories, PNL-6698, (1988).

(27) C.I. Steefel and P. Van Cappellen, Geochim. Cosmochim. Acta, 54, 2657-2677 (1990).

(28) D.M. Strachan, B.P. McGrail, M.J. Apted, D.W. Engel and P.W. Eslinger, 'Preliminary assessment of the controlled release of radionuclides from waste packages containing borosilicate waste glass", Pacific Northwest Laboratory, PNL$7591,(1990)$.

(29) W.L. Ebert, J.K. Bates, E.C. Buck and C.R. Bradley, Mat. Res. Soc. Symp. Proc., (in press), (1993).

(30) A. Barkatt, E.E. Saad, R. Adiga, W. Sousanpour, A. Barkatt and M.A. Adel-Hadadi, Appl. Geochem., 4, 593-603 (1989).

(31) J.C. Tait and C.D. Jensen, J. Non-Cryst. Solids, 49, 363-377 (1982).

(32) C.T. Lee and D.E. Clark, in Advances in Ceramics, Vol. 20American Ceramic Society: 1986.

(33) G. Bart, H.U. Zwicky, E.T. Aerne, T. Graber, D. Z Berg and M. Tokiwai, Mat. Res. Soc. Symp. Proc., 84, 459-470 (1987).

(34) B. Grambow, H.U. Zwicky, G. bart, I.K. Björner and L.O. Werme, Mat. Res. Soc. Symp. Proc., 84, 471-481 (1987).

(35) Z. Andriambololona, N. Godon and E. Vernaz, Mat. Res. Soc. Symp. Proc., 252, 151158 (1992). 
(36) M.J. Plodinec, C.M. Jartzen and G.G. Wi`ck, Mat. Res. Soc. Symp. Proc., 26, 755-762 (1984).

(37) C.M. Jantzen and M.J. Plodinec, Journal of Non-Crystalline Solids, 67, 207-223 (1984).

(38) B. Grambuw Ph.D. Thesis, Freien Universität Berlin, 1984.

(39) K.G. Knauss, W.L. Bourcier, K.D. McKeegan, C.I. Merzbacher, S.N. Nguyen, F.J. Ryerson, D.K. Smith, H.C. Weed and L. Newton, Mat. Res. Soc. Symp. Proc., 176, $37 i-381$ (1990).

(40) C.M. Jantzen, in Corrosion of Class, Ceramics, and Ceramic Superconductors; D. E. Clark and B. K. Zoitos, Ed.; Noyes Publications: Park Ridge, New Jersey, 1992; pP 153-215.

(41) A. Barkatt, A. Olszowka, W. Sousanpour, M.A. Adel-Hadadi, R. Adiga, A. Baraktt, G.S. Marbury and S. Li, Mat. Res. Soc. Symp. Proc., 212, 65-76 (1991).

(42) J. Patyn, P. Van Iseghem and W. Timmermans, Mat. Res. Soc. Symp. Proc., 176, 299307 (1990).

(43) P. Van Iseghem, T. Ameya, Y. Suzuki and H. Yamamoto, J. Nuc. Materials, 190, 269 276 (1992).

(44) J.C. Sang, A. Barkatt, I.G. Talmy and M.K. Norr, Mat. Res. Soc. Symp. Proc., 294, 583-589 (1993).

(45) E. Curti, "Modelling the dissolution of borosilicate glasses for radioactive waste disposal with the PHREEQE/GLASSOL code: theory and practice", Paul Scherrer Institute, PSI-Bericht Nr. 86, (1991).

(46) B. Grambow, W. Lutze and R. Müller, Mat. Res. Soc. Symp. Proc, 257, 143-150 (1992).

(47) N. Godon, E. Vernaz, J.H. Thomassin and J.C. Touray, Mat. Res. Soc. Symp. Proc., 127, 97-104 (1989).

(48) L Trotignon Ph.D. Thesis, Paul Sabatier University, 1990.

(49) D.M. Strachan, W.I. Bourcier and B.P. McGrail, Radioactive Waste Management and the Fuel Cycle, (in press), (1993). 